International Journal of Applied Dental Sciences 2021; 7(3): 407-411

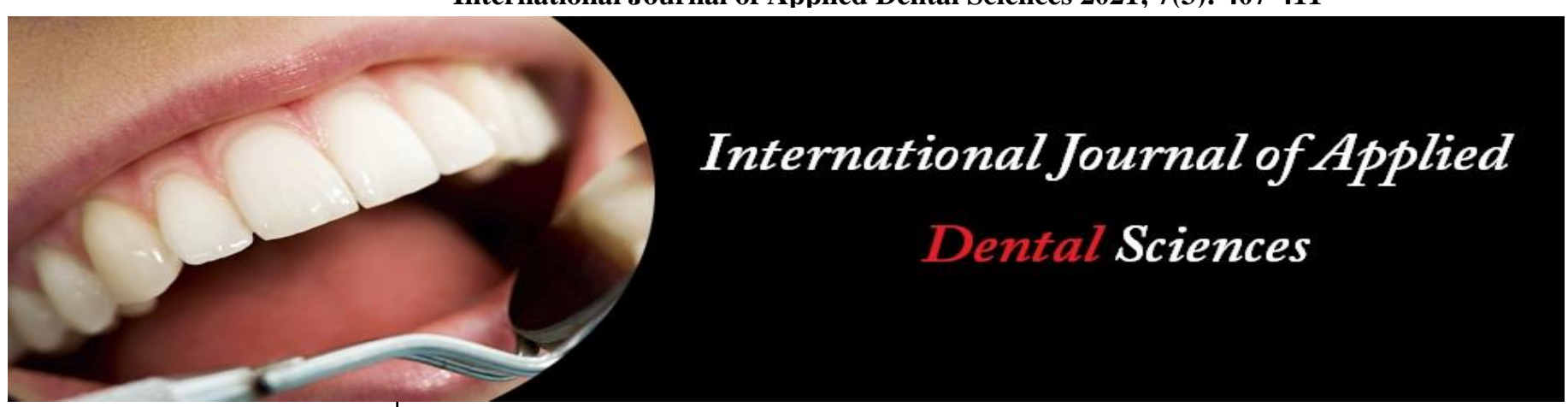

ISSN Print: 2394-7489

ISSN Online: 2394-7497

IJADS 2021; 7(3): 407-411

(C) 2021 IJADS

www.oraljournal.com

Received: 28-05-2021

Accepted: 30-06-2021

Ayşe Karabaş

Specialist Prosthodontist,

Private Dental Practice,

Gaziantep, Turkey

Taha Yaşar Manav

Kahramanmaraş Sütçü İmam

University, Faculty of Dentistry,

Department of Prosthetic

Dentistry, Kahramanmaraş,

Turkey

Hakan Kamalak

Kahramanmaraş Sütçü İmam

University, Faculty of Dentistry,

Department of Restorative

Dentistry, Kahramanmaras,

Turkey
Corresponding Author:

Ayşe Karabaş

Specialist Prosthodontist,

Private Dental Practice,

Gaziantep, Turkey

\section{Relation in color of three regions of human maxillary incisors and canines}

\section{Ayşe Karabaş, Taha Yaşar Manav and Hakan Kamalak}

DOI: https://doi.org/10.22271/oral.2021.v7.i3f.1331

\section{Abstract}

Objective: The aim of this study was to evaluate relations between color distributions in the cervical, middle, and incisal segments of the teeth in the anterior region.

Material and Method: Thirty-one individuals aged between 18-24 participated in the study. Color measurements were performed using VITA Easyshade V (VITA Zahnfabrik, Germany) from the cervical, middle and incisal regions of the left upper central, lateral, and canine teeth of participants. $\mathrm{L}^{*}$, $\mathrm{a}^{*}, \mathrm{~b}^{*}$ values were determined using a spectrophotometer. $\Delta \mathrm{E}$ values were calculated to determine the color difference, and $\mathrm{L}^{*}, \mathrm{a}^{*}, \mathrm{~b} *$ values were statistically analyzed.

Results: Statistically significant results were obtained between $L^{*}, a^{*}, b^{*}$ values of different teeth segments using Spearman's correlation analysis. $\Delta \mathrm{E}$ was calculated higher than 3.7 among all teeth segments.

Conclusions: Using the $\mathrm{L}^{*}$ and $\mathrm{b}^{*}$ values of the middle segment color of the upper lateral tooth, it is possible to calculate the $\mathrm{L}^{*}$ and $\mathrm{b}^{*}$ values of the incisal, middle, and cervical colors of the upper incisors and canines.

Keywords: VITA Easyshade, spectrophotometer, CIELab, color analysis

\section{Introduction}

Human teeth consist of two hard tissues; dentin and enamel. While dentin mainly determines tooth color, enamel represents a minor role through scattering at wavelengths in the blue range [1]. Tooth color is caused by the color of the dentin, the thickness and translucency of the enamel ${ }^{[2]}$. The effect of dentin on tooth color in the cervical part is greater than the middle segment as it is covered by a thinner layer of enamel, whereas enamel partially replaces dentin along the incisal edges ${ }^{[3]}$. As a result, the cervical color is better differentiated from the color in the middle, while the incisal edges transmit the background color. However, the gingiva in the cervical region may discolor the teeth by scattering the reflected light ${ }^{[4]}$.

Tooth color selection methods can be classified into two categories: visual and instrumental methods ${ }^{[5,6]}$. The most popular method of color selection is the visual method using the shade guides. The instrumental method is more objective and provides information on the magnitude and direction of color differences ${ }^{[2]}$.

The development of instrumental color measurement devices such as dental spectrophotometers, colorimeters, spectroradiometers, digital cameras provides accurate tooth color matching ${ }^{[7,8]}$. The spectrophotometer is a photometer that can precisely measure the wavelength of light ${ }^{[9]}$. Dental spectrophotometers are often used by dentists to evaluate the color parameters of natural teeth and restorations ${ }^{[5,10]}$. VITA Easyshade V (VITA Zahnfabrik, Germany) is a portable, cordless, small, contact type and economical color measuring instrument based on shade guides ${ }^{[6]}$.

CIELab color space and color difference formulas are widely used in dentistry for color measurement and color assessment ${ }^{[11]}$. In the CIELab three-dimensional system, each color represents three colorimetric axes: $\mathrm{L}^{*}$ represents the lightness-achromatic axis, $\mathrm{a}^{*}$ represents the green-red axis, and $b^{*}$ the blue-yellow axis ${ }^{[12]}$. The most frequently used formula in the CIE L*a*b* system $^{[4,13,14]}$ 
$\Delta \mathrm{E}=\left(\left(\mathrm{L} *_{1}-\mathrm{L} *_{2}\right)^{2}+\left(\mathrm{a} *_{1}-\mathrm{a} *_{2}\right)^{2}+\left(\mathrm{b} *_{1}-\mathrm{b}^{*}\right)\right)^{1 / 2}$

The color coordinates of the cervical, middle, and incisor regions of the tooth have been compared in previous studies ${ }^{[15]}$. O'Brien [16] showed that there are color differences between the three regions and that these differences are also clinically significant. However, the importance of the relationship between the colors distributed in different regions of vital human central, lateral and canine teeth has not been quantitatively analyzed by a spectrophotometer before. Consequently, it should be possible to predict the color of one tooth segment from the color of another tooth segment in the anterior region. Therefore, the aim of this study is to obtain $L^{*} a^{*} b^{*}$ values of the cervical, middle and incisal segments of vital central, lateral and canine teeth and to evaluate the color relationship between these segments.

\section{Material and Method}

Thirty-one individuals aged between 18-24 participated in the study. Observers were subjected to Ishihara testing before taking part in the study. Individuals who did not have coloration, abnormalities and restoration of their anterior maxillary teeth were included in the study. The shade matching was performed in the same clinic and the same dental chair. Color measurement was measured in natural daylight. Participants sat in the same dental chair with the Frankfurt horizontal plane parallel to the floor. Teeth were moistened with saliva before each measurement, as dry teeth may appear lighter. The VITA Easyshade V (VITA Zahnfabrik, Germany) was calibrated before each measurement. Color measurement was performed from the cervical, middle and incisal regions of the left upper central, lateral and canine teeth using VITA Easyshade V (VITA Zahnfabrik, Germany). L*, a*, b* values of all anterior tooth segments of 19 participants with central middle segment color A1 were recorded in the data table. Twelve individuals with different central tooth colors were not included in the study. In addition, $\Delta \mathrm{E}$ values were calculated between incisor, middle and cervical regions of teeth and $\mathrm{L}^{*}, \mathrm{a}^{*}, \mathrm{~b}^{*}$ values were statistically analyzed.

NCSS (Number Cruncher Statistical System) 2007 (Kaysville, Utah, USA) software was used for statistical analysis. Descriptive statistical methods were used when evaluating the study data, and the distribution of the data was evaluated using the Shapiro-Wilk Test. In addition, Spearman's analysis was performed to detect correlations between different variables. Significance was evaluated at $p<0.01$ and $p<0.05$.

\section{Results}

The $\Delta \mathrm{E}$ value was calculated to evaluate the color difference between tooth segments seen in Table 1. Color differences were found between all regions of the teeth compared in this study. According to the groups, the $\mathrm{L}^{*}, \mathrm{a}^{*}$ and $\mathrm{b}^{*}$ mean values as seen in Table 2 . The image created with the mean $\mathrm{L}^{*}, \mathrm{a}^{*}$, and $\mathrm{b}^{*}$ values of the individuals participating in the study as seen in Figure 1.

In the present study, there was a moderate level of correlation between Central incisal-L* and Central middle-L*. $(r=, 593$, $p<0,01)$

There was a moderate level of correlation between Central incisal-L* and Lateral incisal-L*. $(\mathrm{r}=, 567, p<0,05)$ There was a moderate level of correlation between Central incisal-L* and Canine incisal-L*. $(\mathrm{r}=, 470, \quad p<0,05)$ There was a moderate level of correlation between Lateral incisal-L* and Canine middle-L*. $(\mathrm{r}=, 490, p<0,05)$ There was a moderate level of correlation between Lateral middle- $\mathrm{L}^{*}$ and Lateral cervical-L* $(\mathrm{r}=, 511, p<0,05)$ There was a moderate level of correlation between Lateral middle-L* and Canine cervical$\mathrm{L}^{*}$. $\quad(\mathrm{r}=, 517, \quad p<0,05)$ There was a moderate level of correlation between Canine incisal- $\mathrm{L}^{*}$ and Canine middle- $\mathrm{L}^{*}$. $(\mathrm{r}=, 567, p<0,05)$

There was a high level of correlation between Central middle$\mathrm{L} *$ and Central cervical-L*.(r=,750, $p<0,01)$ There was a high level of correlation between Central incisal-L* and Lateral middle- $\mathrm{L}^{*}$. $(\mathrm{r}=, 600, p<0,01)$ There was a high level of correlation between Central middle- $\mathrm{L}^{*}$ and Lateral middle$\mathrm{L}^{*}$. $(\mathrm{r}=, 614, p<0,01)$ There was a high level of correlation between Central cervical-L* and Lateral cervical-L*. $(r=, 617$, $p<0,01)$ There was a high level of correlation between Lateral incisal- $\mathrm{L}^{*}$ and Lateral middle- $\mathrm{L}^{*}$. $(\mathrm{r}=, 682, p<0,01)$ There was a high level of correlation between Lateral incisal-L* and Canine incisal-L*. $(\mathrm{r}=, 688, p<0,01)$ There was a high level of correlation between Lateral middle- $\mathrm{L}^{*}$ and Canine incisal-L* $(\mathrm{r}=, 734, p<0,01)$ There was a high level of correlation between Lateral middle- $\mathrm{L}^{*}$ and Canine middle-L*. ( $\mathrm{r}=, 649$, $p<0,01)$ There was a high level of correlation between Lateral cervical-L* and Canine cervical-L*. $(\mathrm{r}=, 727, p<0,01)$ There was a high level of correlation between Canine middle- $\mathrm{L}^{*}$ and Canine cervical-L*. $(\mathrm{r}=, 698, p<0,01)$

There was a moderate level of correlation between Central middle-a* and Lateral cervical-a*. $(\mathrm{r}=, 522, p<0,05)$ There was a moderate level of correlation between Central cervical$\mathrm{a}^{*}$ and Lateral incisal-a*. $(\mathrm{r}=, 572, p<0,05)$

There was a high level of correlation between Central middle$\mathrm{a}^{*}$ and Canine cervical-a* $(\mathrm{r}=, 645, p<0,01)$.

There was a moderate level of correlation between Central incisal-b* and Lateral cervical-b*. $(\mathrm{r}=, 591, p<0,05)$. There was a moderate level of correlation between Central incisal$\mathrm{b}^{*}$ and Canine incisal-b*. $(\mathrm{r}=, 509, p<0,05)$ There was a moderate level of correlation between Central incisal-b* and Canine middle- $\mathrm{b}^{*}$. $(\mathrm{r}=, 543, p<0,05)$ There was a moderate level of correlation between Lateral incisal-b* and Lateral cervical-b*. $(\mathrm{r}=, 486, p<0,05)$ There was a moderate level of correlation between Lateral incisal-b* and Canine cervical-b* $(\mathrm{r}=, 517, p<0,05)$ There was a moderate level of correlation between Lateral middle- $\mathrm{b}^{*}$ and Canine incisal- $\mathrm{b}^{*}$. ( $\mathrm{r}=, 505$, $p<0,05)$ There was a moderate level of correlation between Lateral middle- $\mathrm{b}^{*}$ and Canine cervical- $\mathrm{b}^{*}$. $(\mathrm{r}=, 483, p<0,05)$ There was a moderate level of correlation between Lateral cervical- $\mathrm{b}^{*}$ and Canine middle- $\mathrm{b}^{*} .(\mathrm{r}=, 591, p<0,05)$ There was a moderate level of correlation between Lateral cervical$\mathrm{b}^{*}$ and Canine cervical- $\mathrm{b}^{*}$. $(\mathrm{r}=, 491, p<0,05)$ There was a moderate level of correlation between Canine incisal-b* and Canine cervical-b*. $(\mathrm{r}=, 503, p<0,05)$

There was a high level of correlation between Central incisal $\mathrm{b}$ and Central middle- $\mathrm{b}^{*}$.( $\left.\mathrm{r}=, 672, p<0,01\right)$ There was a high level of correlation between Central incisal-b* and Central cervical- $\mathrm{b}^{*}$. $(\mathrm{r}=, 614, p<0,01)$ There was a high level of correlation between Central incisal-b* and Lateral incisal-b*. $(\mathrm{r}=, 752, p<0,01)$ There was a high level of correlation between Central incisal-b* and Lateral middle-b*. ( $r=, 699$, $p<0,01)$ There was a high level of correlation between Central middle- $\mathrm{b}^{*}$ and Lateral middle- $\mathrm{b}^{*}$. $(\mathrm{r}=, 597, p<0,01)$ There was a high level of correlation between Central middle-b* and Lateral cervical-b*. $(\mathrm{r}=, 742, p<0,01)$ There was a high level of correlation between Central cervical-b* and Lateral middle- $\mathrm{b}^{*}$. $(\mathrm{r}=, 683, p<0,01)$ There was a high level of correlation between Central cervical-b* and Lateral cervical$\mathrm{b}^{*}$. $(\mathrm{r}=, 677, p<0,01)$ There was a high level of correlation between Lateral incisal- $b^{*}$ and Lateral middle- $b^{*}$. $(r=, 655$, 
$p<0,01)$ There was a high level of correlation between Lateral incisal-b* and Canine incisal- $\mathrm{b}^{*} .(\mathrm{r}=, 720, p<0,01)$ There was a high level of correlation between Lateral incisal-b* and Canine middle- $\mathrm{b}^{*}$. $(\mathrm{r}=, 692, p<0,01)$ There was a high level of correlation between Lateral middle- $b^{*}$ and Lateral cervical$\mathrm{b}^{*}$. ( $\mathrm{r}=$,793, $\left.p<0,01\right)$ There was a high level of correlation between Canine middle- $\mathrm{b}^{*}$ and Canine cervical- $\mathrm{b}^{*}$. $(\mathrm{r}=, 712$, $p<0,01$ )

There was very high level of correlation between Central middle- $\mathrm{b}^{*}$ and Central cervical- $\mathrm{b}^{*}$. $(\mathrm{r}=, 819, p<0,01)$. There was very high level of correlation between Lateral middle-b* and Canine middle- $\mathrm{b} *$. $(\mathrm{r}=, 814, p<0,01)$

\section{Discussion}

In the present study, there is a relationship between the color of the incisal, middle and cervical segments of the central, lateral and canine teeth.

Measurements using a spectrophotometer give accurate results due to its easy and automatic operation ${ }^{[17]}$. Accurately results can be obtained by calibration before each measurement. In this study, the VITA Easyshade V (VITA Zahnfabrik, Germany) spectrophotometer was used to analyze the color distribution on vital tooth surfaces and determine the color of natural teeth. The clinical accuracy of Vita Easyshade spectrophotometers has been confirmed in previous research $[5,18]$

In this study, the first color measurement was made from the middle region of the central tooth. Discoloration, white spot, and translucent areas in the incisal region may adversely affect color detection. In this study, individuals with color changes such as discoloration and white spot were excluded, but incisal color measurements may be affected due to translucency. In addition, in the gingival region, incorrect measurements can be made due to the contrast of the gingiva with the tooth ${ }^{[19]}$

Only individuals with A1 color in the central middle segment were included in the study. The reason for this criterion is to provide standardization when calculating color comparisons and relationships between different teeth segments.

The $\Delta \mathrm{E}$ value was calculated to evaluate the color difference between tooth segments. It has been reported that $\Delta \mathrm{E}=3.7$ is a clinically acceptable threshold of visual perception in the CIELab system ${ }^{[20,21]}$ Color differences were found between all regions of the teeth compared in this study. Similar to the results of a previous study comparing only the color difference between the three regions of the central tooth ${ }^{[3]}$. Different colors of cervical, middle and incisal regions of the same tooth; can be explained by the fact that the dentin and enamel thicknesses differ according to the regions. Moreover, a statistically significant relation in color between the tooth segments of the anterior maxillary teeth was reported ${ }^{[22]}$.

As a result of the correlation analysis, positive relationships were found between the $L^{*}, a^{*}, b^{*}$ values of the tooth regions. These relationships are notably seen in $\mathrm{L}^{*}$ and $\mathrm{b}^{*}$ values. A positive correlation was found between the middle region of the lateral tooth and all regions of the central, lateral and canine teeth, except the incisal of the lateral tooth, in the $\mathrm{L}^{*}$ value. (Table 3 ) It may be possible to calculate the $\mathrm{L}^{*}$ values of all anterior teeth from the $\mathrm{L}^{*}$ value of only the middle region of the lateral tooth.

The relations between the tooth regions in the $b^{*}$ coordinate value are similar to the relations in the $\mathrm{L}^{*}$ value. A positive correlation was found between the middle region of the lateral tooth and all central, lateral and canine teeth regions in $b^{*}$ value. (Table 5) It may be possible to calculate the $b^{*}$ values of all anterior teeth from the $b^{*}$ value of only the middle region of the lateral tooth.

According to the present study, only three regions were correlated with the $\mathrm{a}^{*}$ color coordinate values of the tooth segments. (Table 4) Contrary to the $L^{*}$ and $b^{*}$ values, the $a^{*}$ value shows a random distribution in the tooth regions.

Đozic et al. ${ }^{[22]}$ found a positive correlation between the $\mathrm{L}^{*}$ and $b^{*}$ values of the incisal, middle and cervical regions of the upper incisors and canines and showed that the $a^{*}$ value was randomly distributed.

One of the most challenging tasks of a dentist is matching a color. Dentists most frequently consider the reference tooth the contralateral or adjacent tooth, but other teeth are often evaluated to obtain a clinically acceptable color. [5] Unfortunately, this study shows that using the colors of the adjacent teeth in color selection will result in the wrong color selection.

The limitations of this study are the measurement of color only in the anterior teeth, the use of a single instrument while measuring, the inability to convert the measured $\mathrm{L}^{*}, \mathrm{a}^{*}, \mathrm{~b}^{*}$ values to the reference shade guide, and not being able to be used in communication with the technician.

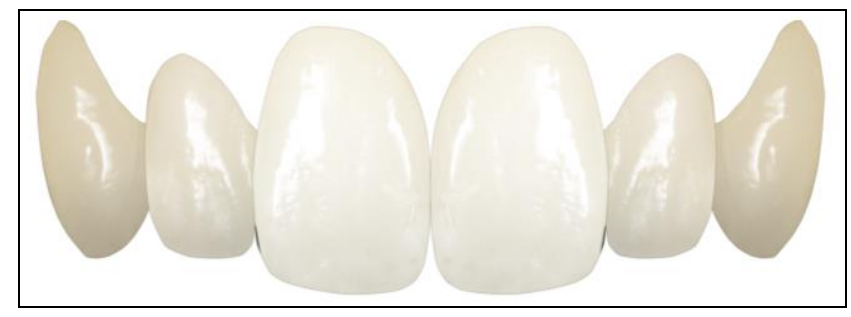

Fig 1: The image created with the mean $L, a, b$ values of the individuals participating in the study

Table 1: $\Delta \mathrm{E}$ values between different anterior tooth segments

\begin{tabular}{|c|c|c|c|c|c|c|c|c|c|c|}
\hline \multicolumn{2}{|c|}{ Anterior Tooth Segments } & Ce-i & Ce-m & Ce-c & L-i & L-m & L-c & Ca-i & Ca-m & Ca-c \\
\hline Central - incisal (Ce-i) & $\Delta \mathrm{E}$ & 0 & & & & & & & & \\
\hline Central - middle (Ce-m) & $\Delta \mathrm{E}$ & 12,42 & 0 & & & & & & & \\
\hline Central - cervical (Ce-c) & $\Delta \mathrm{E}$ & 16,38 & 6,46 & 0 & & & & & & \\
\hline Lateral - incisal (L-i) & $\Delta \mathrm{E}$ & 9,71 & 18,91 & 21,06 & 0 & & & & & \\
\hline Lateral - middle (L-m) & $\Delta \mathrm{E}$ & 12,16 & 7,66 & 6,72 & 14,98 & 0 & & & & \\
\hline Lateral - cervical (L-c) & $\Delta \mathrm{E}$ & 15,88 & 12,18 & 9,34 & 17,23 & 7,14 & 0 & & & \\
\hline Canine - incisal (Ca-i) & $\Delta \mathrm{E}$ & 14,83 & 23,33 & 24,22 & 8,57 & 18,13 & 18,29 & 0 & & \\
\hline Canine - middle (Ca-m) & $\Delta \mathrm{E}$ & 14,93 & 14,34 & 11,78 & 14,71 & 7,67 & 7,59 & 15,31 & 0 & \\
\hline Canine - cervical (Ca-c) & $\Delta \mathrm{E}$ & 17,48 & 15,80 & 12,76 & 18,00 & 10,09 & 7,20 & 17,29 & 5,60 & 0 \\
\hline
\end{tabular}


Table 2: The mean values of $L^{*}, a^{*}, b^{*}$ of anterior tooth segments.

\begin{tabular}{|c|c|c|c|}
\hline Anterior Tooth Segments & $\mathbf{L}^{*}$ & $\mathbf{a}^{*}$ & $\mathbf{b}^{*}$ \\
\hline Central incisal & 75,07 & $-1,72$ & 12,39 \\
\hline Central middle & 86,42 & $-1,80$ & 15,74 \\
\hline Central cervical & 87,22 & 0,30 & 21,32 \\
\hline Lateral incisal & 68,55 & $-0,23$ & 13,10 \\
\hline Lateral middle & 81,46 & 0,19 & 19,75 \\
\hline Lateral cervical & 79,58 & 2,21 & 22,97 \\
\hline Canine incisal & 64,12 & 1,03 & 16,61 \\
\hline Canine middle & 76,79 & 1,55 & 23,76 \\
\hline Canine cervical & 77,06 & 2,13 & 26,45 \\
\hline
\end{tabular}

Table 3: Correlations between $\mathrm{L}^{*}$ values of anterior tooth segments

\begin{tabular}{|c|c|c|c|c|c|c|c|c|c|c|}
\hline \multicolumn{2}{|c|}{ Anterior Tooth Segments } & Ce-i & Ce-m & Ce-c & L-i & L-m & L-c & Ca-i & Ca-m & Ca-c \\
\hline \multirow{2}{*}{$\begin{array}{c}\text { Central - incisal } \\
(\mathrm{Ce}-\mathrm{i})\end{array}$} & $\mathrm{r}$ & 1 & & & & & & & & \\
\hline & $p$ & & & & & & & & & \\
\hline \multirow{2}{*}{$\begin{array}{l}\text { Central - middle } \\
(\mathrm{Ce}-\mathrm{m})\end{array}$} & $\mathrm{r}$ &, $593 * *$ & 1 & & & & & & & \\
\hline & $\mathrm{p}$ &, 009 & & & & & & & & \\
\hline \multirow{2}{*}{$\begin{array}{c}\text { Central - cervical } \\
(\mathrm{Ce}-\mathrm{c})\end{array}$} & $\mathrm{r}$ & 0,357 & ,750** & 1 & & & & & & \\
\hline & $\mathrm{p}$ &, 146 &, 000 &. & & & & & & \\
\hline \multirow{2}{*}{$\begin{array}{l}\text { Lateral - incisal } \\
(\mathrm{L}-\mathrm{i})\end{array}$} & $\mathrm{r}$ &, $567 *$ &, 176 & 0,059 & 1 & & & & & \\
\hline & $\mathrm{p}$ &, 014 &, 484 &, 817 & . & & & & & \\
\hline \multirow{2}{*}{$\begin{array}{c}\text { Lateral - middle } \\
(\mathrm{L}-\mathrm{m})\end{array}$} & $\mathrm{r}$ &, $600 * *$ &, $614 * *$ & 0,405 &, $682 * *$ & 1 & & & & \\
\hline & $\mathrm{p}$ & ,009 &, 007 &, 096 &, 002 & & & & & \\
\hline \multirow{2}{*}{$\begin{array}{c}\text { Lateral - cervical } \\
(\mathrm{L}-\mathrm{c})\end{array}$} & $\mathrm{r}$ & 0,028 & 0,459 &, $617 * *$ & 0,195 &, $511 *$ & 1 & & & \\
\hline & $\mathrm{p}$ & ,913 &, 055 &, 006 &, 438 &, 030 & & & & \\
\hline \multirow{2}{*}{$\begin{array}{c}\text { Canine - incisal } \\
(\mathrm{Ca}-\mathrm{i})\end{array}$} & $\mathrm{r}$ & $470 *$ & ,296 & 0,168 &, $688 * *$ & $734 * *$ & 0,191 & 1 & & \\
\hline & $\mathrm{p}$ & 0,049 & ,233 &, 504 &, 002 & , 001 & ,448 & & & \\
\hline \multirow{2}{*}{$\begin{array}{c}\text { Canine - middle } \\
(\mathrm{Ca}-\mathrm{m})\end{array}$} & $\mathrm{r}$ &, 143 & 0 & 0,062 & $490 *$ & ,649** & 0,424 & ,567* & 1 & \\
\hline & $\mathrm{p}$ &, 570 & 0,358 &, 807 &, 039 &, 004 &, 079 &, 014 & . & \\
\hline \multirow{2}{*}{$\begin{array}{c}\text { Canine - cervical } \\
(\mathrm{Ca}-\mathrm{c})\end{array}$} & $\mathrm{r}$ & 0,085 & 0,339 & 0 & 0,146 &, $517 *$ &, $727 * *$ & 0,249 &, $698 * *$ & 1 \\
\hline & $\mathrm{p}$ &, 738 &, 169 & 0,066 &, 564 &, 028 &, 001 &, 319 &, 001 & . \\
\hline
\end{tabular}

Spearman's $* p<0,05 * * p<0,01$

Table 4: Correlations between $a^{*}$ values of anterior tooth segments

\begin{tabular}{|c|c|c|c|c|c|c|c|c|c|c|}
\hline \multicolumn{2}{|c|}{ Anterior Tooth Segments } & Ce-i & Ce-m & Ce-c & L-i & L-m & L-c & Ca-i & Ca-m & Ca-c \\
\hline \multirow{2}{*}{$\begin{array}{c}\text { Central - incisal } \\
(\mathrm{Ce}-\mathrm{i})\end{array}$} & $\mathrm{r}$ & 1,000 & & & & & & & & \\
\hline & $\mathrm{p}$ & & & & & & & & & \\
\hline \multirow{2}{*}{$\begin{array}{l}\text { Central - middle } \\
(\text { Ce-m) }\end{array}$} & $\mathrm{r}$ & 0,175 & 1 & & & & & & & \\
\hline & $\mathrm{p}$ &, 488 & . & & & & & & & \\
\hline \multirow{2}{*}{$\begin{array}{c}\text { Central - cervical } \\
(\mathrm{Ce}-\mathrm{c})\end{array}$} & $\mathrm{r}$ & 0,079 & 0,327 & 1 & & & & & & \\
\hline & $\mathrm{p}$ & ,756 &, 186 & & & & & & & \\
\hline \multirow{2}{*}{$\begin{array}{c}\text { Lateral - incisal } \\
(\mathrm{L}-\mathrm{i})\end{array}$} & $\mathrm{r}$ & ,172 & 0,077 &, $572 *$ & 1,000 & & & & & \\
\hline & $\mathrm{p}$ &, 495 &, 760 &, 013 & & & & & & \\
\hline \multirow{2}{*}{$\begin{array}{l}\text { Lateral - middle } \\
(\mathrm{L}-\mathrm{m})\end{array}$} & $\mathrm{r}$ & 0,101 & 0,289 & 0,349 & 0,298 & 1 & & & & \\
\hline & $\mathrm{p}$ & ,690 &, 244 &, 155 &, 230 & & & & & \\
\hline \multirow{2}{*}{$\begin{array}{c}\text { Lateral - cervical } \\
(\mathrm{L}-\mathrm{c})\end{array}$} & $\mathrm{r}$ & $-0,234$ &, $522 *$ & 0,15 & 0,203 & 0,168 & 1 & & & \\
\hline & $\mathrm{p}$ &, 350 &, 026 & ,552 &, 419 &, 504 & & & & \\
\hline \multirow{2}{*}{$\begin{array}{c}\text { Canine - incisal } \\
(\mathrm{Ca}-\mathrm{i})\end{array}$} & $\mathrm{r}$ &,- 023 & 0,118 & 0,333 & 247 & $-0,035$ & 0,382 & 1,000 & & \\
\hline & $\mathrm{p}$ & ,928 & ,642 &, 177 & ,323 & ,891 &, 118 & & & \\
\hline \multirow{2}{*}{$\begin{array}{l}\text { Canine - middle } \\
(\mathrm{Ca}-\mathrm{m})\end{array}$} & $\mathrm{r}$ & 0 & 0,127 & 0,297 & 0,441 & $-0,151$ & ,272 & 0,317 & 1 & \\
\hline & $\mathrm{p}$ & 0,656 &, 617 & 231 &, 067 &, 550 & ,274 & ,200 & . & \\
\hline \multirow{2}{*}{$\begin{array}{c}\text { Canine - cervical } \\
(\mathrm{Ca}-\mathrm{c})\end{array}$} & $\mathrm{r}$ & $-0,106$ &, $645^{* * *}$ & 0,42 & $-0,139$ & 0,186 & 0,23 & 0,133 & $-0,051$ & 1,000 \\
\hline & $\mathrm{p}$ &, 676 & 0,004 & ,083 & ,582 & ,461 & ,358 & ,599 &, 841 & \\
\hline
\end{tabular}

Spearman's *p<0,05**p<0,01

Tablo 5: Correlations between $b^{*}$ values of anterior tooth segments

\begin{tabular}{|c|c|c|c|c|c|c|c|c|c|c|}
\hline \multicolumn{1}{|c|}{ Anterior Tooth Segments } & Ce-i & Ce-m & Ce-c & L-i & L-m & L-c & Ca-i & Ca-m & Ca-c \\
\hline $\begin{array}{c}\text { Central }- \text { incisal } \\
(C e-i)\end{array}$ & $\mathrm{r}$ & 1 & & & & & & & & \\
\hline & $\mathrm{p}$ &. & & & & & & & & \\
\hline $\begin{array}{c}\text { Central }- \text { middle } \\
(\text { Ce-m) }\end{array}$ & $\mathrm{r}$ &, $672^{* *}$ & 1 & & & & & & & \\
\hline & $\mathrm{p}$ &, 002 &. & & & & & & & \\
\hline $\begin{array}{c}\text { Central }- \text { cervical } \\
(\text { Ce-c) }\end{array}$ & $\mathrm{r}$ &, $614^{* *}$ &, $819^{* *}$ & 1 & & & & & & \\
\hline & $\mathrm{p}$ &, 007 &, 000 &. & & & & & & \\
\hline $\begin{array}{c}\text { Lateral }- \text { incisal } \\
(\mathrm{L}-\mathrm{i})\end{array}$ & $\mathrm{r}$ &, $752^{* *}$ & 0,285 &, 240 & 1 & & & & & \\
\hline & $\mathrm{p}$ &, 000 &, 251 &, 338 &. & & & & & \\
\hline Lateral - middle & $\mathrm{r}$ &, $699^{* *}$ &, $597^{* *}$ &, $683^{* *}$ &, $655^{* *}$ & 1 & & & & \\
\hline
\end{tabular}




\begin{tabular}{|c|c|c|c|c|c|c|c|c|c|c|}
\hline$(\mathrm{L}-\mathrm{m})$ & $\mathrm{p}$ &, 001 &, 009 &, 002 &, 003 &. & & & & \\
\hline Lateral - cervical & $\mathrm{r}$ &, $591^{* *}$ &, $742^{* *}$ &, $677^{* *}$ &, $486^{*}$ &, $793^{* *}$ & 1 & & & \\
\cline { 2 - 12 }$(\mathrm{L}-\mathrm{c})$ & $\mathrm{p}$ & 0,01 &, 000 &, 002 &, 041 &, 000 &. & & & \\
\hline $\begin{array}{c}\text { Canine - incisal } \\
(\text { Ca-i) }\end{array}$ & $\mathrm{r}$ &, $509^{*}$ & 0 &, 146 &, $720^{* *}$ &, $505^{*}$ &, 456 & 1 & & \\
\hline & $\mathrm{p}$ &, 031 & 0,359 &, 564 &, 001 &, 033 &, 057 &. & & \\
\hline $\begin{array}{c}\text { Canine - middle } \\
(\text { Ca-m) }\end{array}$ & $\mathrm{r}$ &, $543^{*}$ &, 359 & 0 &, $692^{* *}$ &, $814^{* *}$ &, $591^{* *}$ & 0,435 & 1,000 & \\
\cline { 2 - 12 } & $\mathrm{p}$ &, 020 &, 143 & 0,101 &, 001 &, 000 &, 010 &, 071 &. & \\
\hline $\begin{array}{c}\text { Canine - cervical } \\
(\text { Ca-c) }\end{array}$ & $\mathrm{r}$ & 0,454 & 0,375 & 0,238 &, $517^{*}$ &, $483^{*}$ &, $491^{*}$ &, $503^{*}$ &, $712^{* *}$ & 1 \\
\cline { 2 - 12 } & $\mathrm{p}$ &, 058 &, 126 &, 342 & 0,028 &, 042 &, 038 &, 033 &, 001 &. \\
\hline
\end{tabular}

Spearman's *p<0,05**p<0,01

\section{Conclusions}

There is a clinically noticeable color difference between all segments of the anterior maxillary teeth. Using the $\mathrm{L}^{*}$ and $\mathrm{b}^{*}$ values of the middle segment color of the upper lateral tooth, it is possible to calculate the $\mathrm{L}^{*}$ and $\mathrm{b}^{*}$ values of the incisal, middle, and cervical colors of the upper incisors and canines.

\section{Reference}

1. Ten Bosch J, Coops J. Tooth color and reflectance as related to light scattering and enamel hardness. Journal of dental research 1995;74:374-380.

2. Trifkovic B, Powers JM, Paravina RD. Color adjustment potential of resin composites. Clinical oral investigations 2018;22:1601-1607.

3. Đozic A, Kleverlaan CJ, Aartman IH et al. Relation in color of three regions of vital human incisors. Dental materials 2004;20:832-838.

4. Rutkūnas V, Dirsè J, Bilius V. Accuracy of an intraoral digital scanner in tooth color determination. The Journal of prosthetic dentistry 2020;123:322-329.

5. Greța DC, Gasparik C, Colosi HA et al. Color matching of full ceramic versus metal-ceramic crowns-a spectrophotometric study. Medicine and pharmacy reports 2020;93:89.

6. Makhloota M, Köroğlu A, BAL BT A Review of Color Matching in Dentistry. Medical Records 3, 44-49.

7. Revilla-León M, Methani MM, Özcan M. Impact of the ambient light illuminance conditions on the shade matching capabilities of an intraoral scanner. Journal of Esthetic and Restorative Dentistry 2020.

8. Ballard E, Metz MJ, Harris BT et al. Satisfaction of Dental Students, Faculty, and Patients with Tooth Shade-Matching Using a Spectrophotometer. Journal of dental education 2017;81:545-553.

9. Smitha A, Savitha P. Shade matching in aesthetic dentistry-from past to recent advances. J Dent Oral Care Med 2017;3:102.

10. Ebeid K, Sabet A, Della Bona A. Accuracy and repeatability of different intraoral scanners on shade determination. Journal of Esthetic and Restorative Dentistry 2020.

11. Pérez MM, Herrera LJ, Carrillo F et al. Whiteness difference thresholds in dentistry. Dental Materials 2019;35:292-297.

12. Pop-Ciutrila I-S, Ghinea R, Colosi HA et al. Color compatibility between dental structures and three different types of ceramic systems. BMC Oral Health 2021;21:1-10.

13. Igiel C, Weyhrauch M, Wentaschek S et al. Dental color matching: A comparison between visual and instrumental methods. Dental materials journal 2016;35:63-69.

14. Mahn E, Tortora SC, Olate B et al. Comparison of visual analog shade matching, a digital visual method with a cross-polarized light filter, and a spectrophotometer for dental color matching. The Journal of prosthetic dentistry
2021;125:511-516.

15. Kobayashi I. A Study on the Esthetic Coloring of Tooth by Spectroradiometory-Concerning the Maxillary Anterior Teeth of the Middle and Old Aged People. J Jpn Prothodont Soc 1988;32:439-448.

16. O'Brien WJ, Hemmendinger H, Boenke KM et al. Color distribution of three regions of extracted human teeth. Dental Materials 1997;13:179-185.

17. Brandt J, Nelson S, Lauer H-C et al. In vivo study for tooth colour determination-visual versus digital. Clinical oral investigations 2017;21:2863-2871.

18. Lehmann K, Devigus A, Wentaschek S et al. Comparison of visual shade matching and electronic color measurement device. Int J Esthet Dent 2017, 12.

19. Hampé-Kautz V, Salehi A, Senger B et al. A comparative in vivo study of new shade matching procedures. International Journal of Computerized Dentistry 2020;23:317-323.

20. Sampaio CS, Atria PJ, Hirata R et al. Variability of color matching with different digital photography techniques and a gray reference card. The Journal of prosthetic dentistry 2019;121:333-339.

21. Tam W, Lee H. Dental shade matching using a digital camera. Journal of dentistry 2012;40:e3-e10.

22. Đozić A, Kleverlaan CJ, Aartman IH et al. Relation in color among maxillary incisors and canines. Dental materials 2005;21:187-191. 